九州大学学術情報リポジトリ

Kyushu University Institutional Repository

\title{
Variable Fertilizer Recommendation for Grass Production by Image-based Growth Status
}

KABIR, Md. Shaha Nur

College of Agriculture and Life Sciences, Chungnam National University

CHUNG, Sun-Ok

College of Agriculture and Life Sciences, Chungnam National University

JANG, Bo-Eun

College of Agriculture and Life Sciences, Chungnam National University

KIM, Yong-Joo

College of Agriculture and Life Sciences, Chungnam National University

他

https://doi.org/10.5109/2232298

出版情報 : 九州大学大学院農学研究院紀要. 64 (1), pp. 145-155, 2019-02-28. 九州大学大学院農学研究 院

バージョン:

権利関係 : 


\title{
Variable Fertilizer Recommendation for Grass Production by Image-based Growth Status
}

\section{Md. Shaha Nur KABIR ${ }^{1,2}$, Sun-Ok CHUNG ${ }^{1 *}$, Bo-Eun JANG ${ }^{1}$, Yong-Joo KIM ${ }^{1}$, Geung-Joo LEE ${ }^{1}$, Kyeong-Hwan LEE ${ }^{3}$, Takashi OKAYASU and Eiji INOUE}

\author{
Laboratory of Agricultural Machinery and Production Systems Design, Division of Bioproduction \\ Environmental Sciences, Department of Agro-environmental Sciences, Faculty of Agriculture, \\ Kyushu University, Fukuoka 819-0395, Japan \\ (Received October 31, 2018 and accepted November 12, 2018)
}

\begin{abstract}
Mowing and fertilizer application are important field operations for proper grass growth management. Because grass growth is not uniform across fields, variable rate fertilization may be an effective method for achieving high grass yields and enhancing fertilizer use efficiency. The objective of this research was to recommend variable rate fertilization for sod production fields depending on site-specific grass growth levels estimated by CCD camera images. CCD images were acquired from three different sod production fields and calibration relationships were obtained between the sensor measurements and the grass growth levels. Based on the calibrations, fertilizer application rates were site-specifically recommended based on expert experience. The grass growth levels and the fertilizer requirements were mapped for the three fields through geostatistical analyses. For the analysis of the spatial variation of growth level and mapping, geostatistical methods such as variogram modeling and Kriging interpolation were used. Linear relationships were obtained for the calibrations between the image-processed results and grass growth levels. Inverse linear relationships between fertilizer recommendations and grass growth levels were obtained with $\mathrm{R}^{2}$ of $0.966,0.971$, and 0.944 for $90 \%, 70 \%$, and $50 \%$ grass growth coverage fields. Exponential models were found to best fit data for $90 \%$ and $50 \%$ grass growth coverage fields with $\mathrm{R}^{2}$ of 0.843 and 0.780 , respectively. Whereas, a spherical model was found to best fit data for $70 \%$ growth grass coverage field with $\mathrm{R}^{2}$ of 0.968 . Turfgrass growth levels were divided into $0(0 \%)$ to $10(100 \%)$ levels, and accordingly, fertilization levels of $10(100 \%)$ to $0(0 \%)$ levels were recommended. The interpolated maps showed a recommended fertilizer application range of $0.5(5 \%) \sim 1.0(10 \%), 0.5(5 \%) \sim 1.5(15 \%)$, and $2.0(20 \%) \sim 4.0(40 \%)$ levels in the middle areas for $90 \%, 70 \%$, and $50 \%$ growth coverage fields, respectively. Whereas, ranges of $3.5(35 \%) \sim 4.7$ (47\%), $3.0(30 \%) \sim 4.0(40 \%)$, and $2.0(20 \%) \sim 3.0$ (30\%) levels were recommended in the edge areas of 90\%, $70 \%$, and $50 \%$ growth coverage fields, respectively. This study could contribute to increase fertilizer use efficiency, reduce environmental contamination, and improve grass quality and growth if the recommended fertilizers are variably applied.
\end{abstract}

Key words: precision agriculture, grass growth, image processing, variable fertilizer recommendation, geostatistics

\section{INTRODUCTION}

Sod production has increased in developed and developing countries as a profitable alternative to many traditional agricultural enterprises (Aldous et al., 2007; Yi, 2012). The turfgrass-sod industry is growing rapidly due to strong demand as a result of its functional, recreational, and aesthetic benefits in urban landscapes (Haydu et al., 2006; Monteiro, 2017). The sod cultivation area in Korea has increased by 3,056 ha (17.8\%) in 2011 compared to sod production in 2006 (13.6\%) (Choi and Yang, 2006; Korea Forest Service, 2012; Youn et al., 2005; Youn et al., 2006).

Mowing is one of the key cultural practices for producing a healthy, dense stand of turf as mowing too low or even too high could stress the turfgrass. Fertilization is also an important issue for turf growth management

${ }^{1}$ College of Agriculture and Life Sciences, Chungnam National University, Daejeon, Republic of Korea

Faculty of Engineering, Hajee Mohammad Danesh Science and Technology University, Dinajpur, Bangladesh

College of Agriculture and Life Sciences, Chonnam National University, Gwangju, Republic of Korea

* Corresponding author (E-mail: sochung@cnu.ac.kr) and has a major influence on achieving a balance between shoot growth and root development of the transplanted sod (White et al., 1991) as excessive nitrogen rates retard root development of the transplanted sod (Duble, 2001). Applying the right amount of nitrogen at different locations in the field is very important for healthy plant growth (Bean et al., 2012). Otherwise growth would not be uniform, showing better growth in some parts and less growth in other parts of the field.

Variable rate fertilization (VRF) has been an important issue in precision agriculture, and an emerging need for reducing the cost of production and environmental contamination (Ruicheng et al., 2013). It allows the farmer to apply different rates of fertilizer at each location across fields to satisfy site-specific management requirements (Koch et al., 2004; Farooque et al., 2012; Huang et al., 2013). This VRF technique can improve fertilization efficiency and protect the environment, and can be achieved by adjusting the application rate based on an electronic map or real-time sensor-based measurement of a continuous stream of information (Grisso et al., 2011). Several studies have been reported on the application of VRF in precision agriculture (Murdock and Howe, 1997; Wells and Dollarhide, 1998; Chan et al., 2002; Ying-zi et al., 2015; Reyes et al., 2015; Gourevitch 
et al., 2018). The implementation of VRF depends on the characterization of spatial variability within a field. Therefore, geostatistical analysis was performed to assess the spatial variation of grass growth of the sod production fields.

For successful VRF, sensing of crop growth, understanding the variability, and application recommendations should be established. Fricke et al. (2011) used an ultrasonic sensor to measure sward height and predicted forage mass with mean residuals ranged between 0.893 and 1.672. Pittman et al. (2015) examined a combination of sensors (laser, ultrasonic, and spectral) for the estimation of biomass yield and plant height in several forage species. Image processing is a popular method to estimate crop growth in different fields of agricultural applications. The texture of an image is a function of the spatial variation in pixel intensities (Tuceryan and Jain, 1998) and is easily perceived by humans (Rosenfeld and Kak, 1982). Some aspects of texture are readily extracted and expressed in numerical form (Chan and McCarty, 1990). Philipp and Rath (2002) compared different transformations of RGB color spaces, and logarithmic discriminant analysis was found to be the most effective method for separating plants and background in color images taken by a digital photo camera. Research on weed/corps discrimination for automatic identification with real-time image processing has also increased recently. Image processing for weed detection is mostly done in two steps, such as segmentation of vegetation against the background (soil and/or harvest residues) and detection of the vegetation pixels that represent weeds (Burgos-Artizzu et al., 2011). In segmentation procedures of vegetation, all pixels belonging to vegetation can be easily extracted by some combination of the color planes on the RGB model (e.g., Woebbecke et al., 1995; Andreasen et al., 1997; Pérez et al., 2000; Aitkenhead et al., 2003; Yang et al., 2003; Ribeiro et al., 2005; Van Evert et al., 2006). The performance of potential sensors such as CCD cameras, ultrasonic modules, and optical reflectance sensors were compared for grass growth estimation under different turfgrowth levels and sensor operation conditions by Kabir et al. (2016). The CCD camera proved to have the feasibility of grass growth detection in different operating conditions.

Variability analysis and mapping of grass growth could be used to reflect the need for fertilization in a turfgrass growing area. Research has been conducted to develop spatial variable fertilization systems for different crops (Raun et al., 2005; Basso et al., 2011; Basso et al., 2016; Farooque et al., 2012; Xu et al., 2015; Ha et al., 2015). Xu et al. (2014a, 2014b) developed a Nutrient Expert (NE) for Hybrid Maize fertilizer recommendation system, a promising nutrient decision support tool, that not only increased grain yield, nutrient use efficiency and profit, but also reduced nutrient loss and environmental pollution. Liu et al. (2017) proposed a method for formulating recommended fertilizer rates for rice using agronomic efficiencies and a sustainable yield index (SYI), and recommended mean $\mathrm{N}, \mathrm{P}_{2} \mathrm{O}_{5}$, and $\mathrm{K}_{2} \mathrm{O}$ fertilization rates of 186, 60, and $96 \mathrm{~kg} / \mathrm{ha}$, respectively, in the study region. Carey et al. (2012) documented turfgrass fertilization practices such as the proper combination of fertilizer rate, timing, and placement that maximized nutrient utilization efficiency and their impacts on urban water quality. Efficient grass growth mapping can be useful for the implementation of timely and site-specific fertilizer management for high-quality turfgrass growth. Based on the maps, a grass field can be divided into different zones to allow growers to use different techniques according to the conditions in each area of the grass field. The fertilizer application maps are useful to indicate the amount of fertilizer required in each zone, and variable rate fertilization could be used to apply the average rate of fertilizer in each zone of the field.

The objective of this study was to recommend variable rate fertilization for sod production fields with grass coverage density of about $90 \%, 70 \%$, and $50 \%$, based on site-specific grass growth levels estimated by CCD camera images.

\section{MATERIALS AND METHODS}

\section{Concept of the variable rate fertilizer recommen- dation}

The concept of variable rate fertilizer recommendation using image sensor-based turfgrass growth mapping is shown in Fig. 1. This map-based variable rate fertilization consists of three parts: sensing of turfgrass growth information, interpolation and mapping, and variable rate fertilizer recommendation. In the first step, the turfgrass growth status of three different turfgrass fields covering 90\%, 70\%, and 50\% turfgrass were sensed using an image sensor (CCD camera). Then the images were processed to identify the turfgrass growth status of the field and calibration was done to recommend fertilizer for different turfgrass growth levels. The turfgrass growth maps for each field were derived from image sensor data and the position of the field acquired by a global positioning system (GPS). Finally, variable rate fertilizer was recommended based on the turfgrass growth levels for each of the sod production fields.

\section{Field sites and image acquisition}

Grass image sets were obtained for sod production fields in the southern part of South Korea in three different field conditions with grass coverage density of about $90 \%\left(720 \mathrm{~m}^{2}\right.$; $\left.35^{\circ} 15^{\prime} \mathrm{N}, 126^{\circ} 61^{\prime} \mathrm{E}\right), 70 \%$ (900 m²; 35 $16^{\prime}$ $\left.\mathrm{N}, 126^{\circ} 63^{\prime} \mathrm{E}\right)$, and $50 \%\left(800 \mathrm{~m}^{2} ; 35^{\circ} 17^{\prime} \mathrm{N}, 126^{\circ} 63^{\prime} \mathrm{E}\right)$ reported by a skilled farmer (owner of the farm) who had experience of growing grass for over 10 years. The shapes of the sod production fields, together with travel trajectories in satellite images and the sample images captured by the camera are shown in Fig. 2. The grass variety was Zoysia Japonica Steud (Korean lawngrass). In this region of Korea, Zoysia grass is usually planted from April to May and harvested from September to October about 15 months after planting. During the Zoysia grass growing season in 2013, the average range 


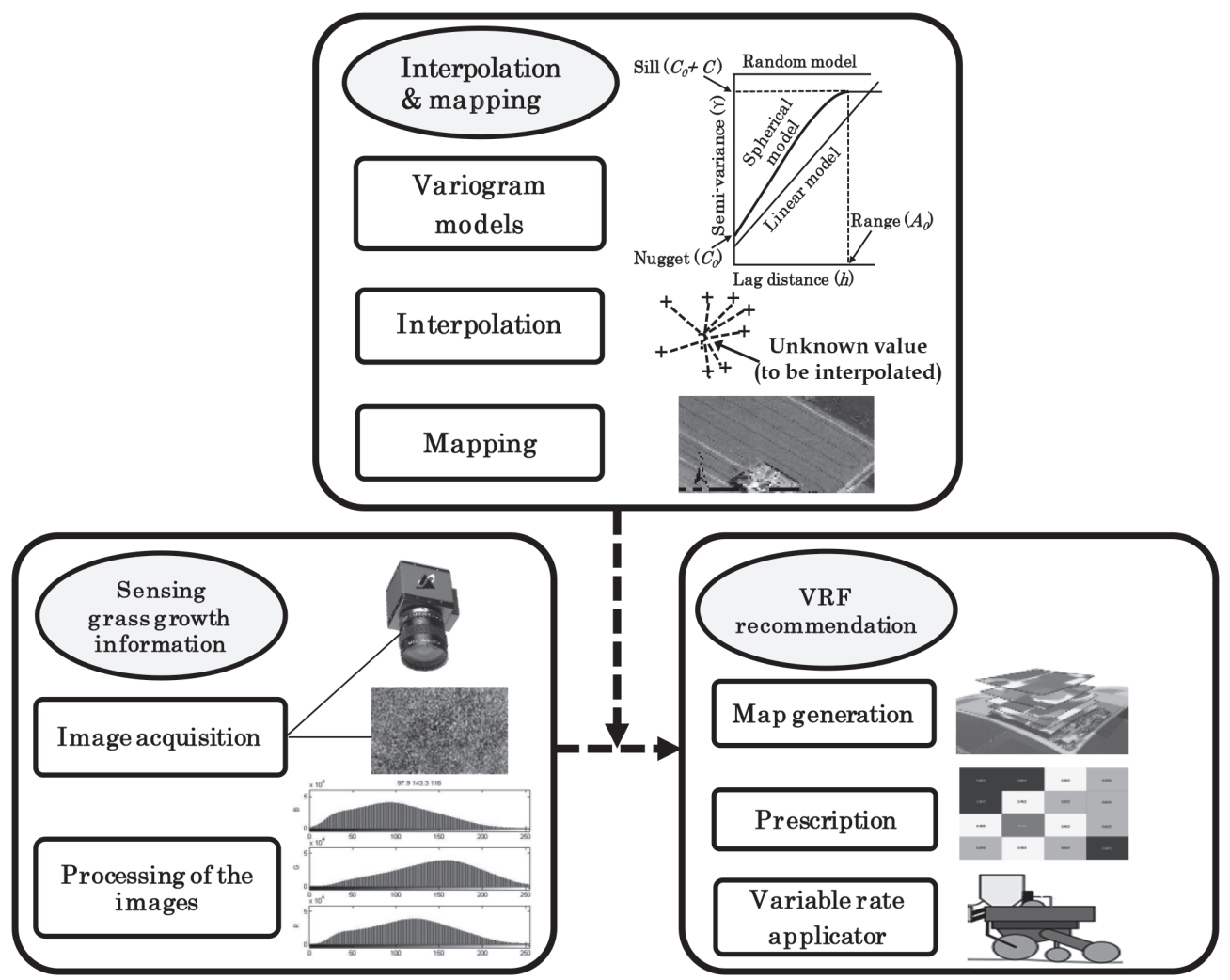

Fig. 1. Schematic diagram showing concept of variable fertilizer (VRF) recommendation based on grass growth maps.
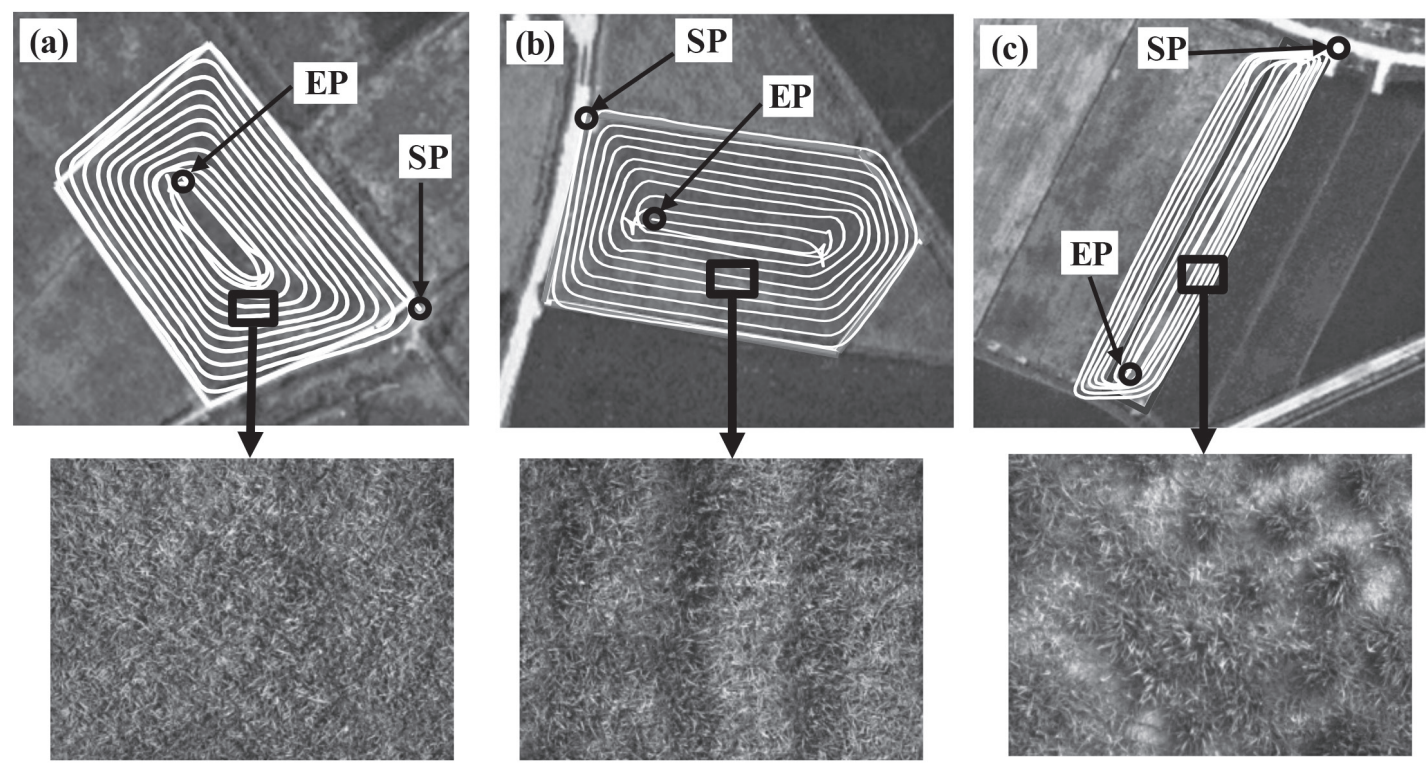

Fig. 2. Grass growth conditions and travel trajectories with starting point (SP) and end point (EP) of growth measurements in three different field conditions: (a) Field 1, 90\% growth; (b) Field 2, 70\% growth; (c) Field 3, 50\% growth.

of monthly temperature and rainfall was $11.4 \sim 28.4^{\circ} \mathrm{C}$ and 30.8 349.1 mm, respectively. The experiments were performed in the middle of September 2013, and the average monthly temperature was $24.5^{\circ} \mathrm{C}$.

In our previous research, a CCD camera was mounted on the top front of a mower tractor at a height of $1.6 \mathrm{~m}$ and pointed downward to the ground (Fig. 3).
The detection area of the CCD camera was $100 \times 50 \mathrm{~cm}^{2}$ and the images were taken from three fields while driving the tractor at 1-m straight line intervals without stopping. Images were taken at 20 points in each field and calibration was done between sensor measurements and growth levels quantified by a skilled expert (Kabir et al., 2016). 


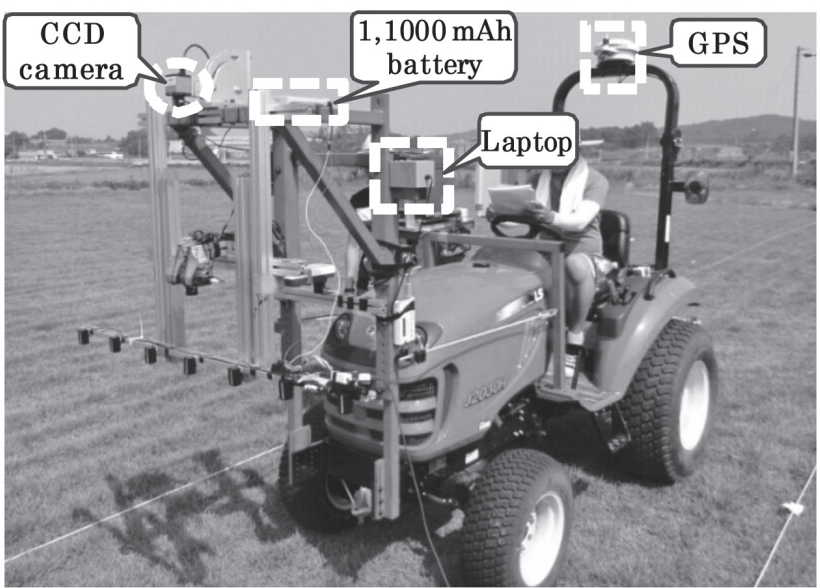

Fig. 3. Grass growth mapping system on the mower tractor.

Therefore, in this research, a CCD camera (model: DFK 31BF03, Sony Co., Japan) with $1280 \times 960$ resolution was used for taking pictures in turfgrass fields without extra illumination, flash or covering. The camera had a $1 / 3$-inch CCD chip and $4.65 \mu \mathrm{m} \times 4.65 \mu \mathrm{m}$ pixel images were possible as three-channel images in the RGB color space. The specifications of the CCD camera are shown in Table 1. Images were captured from each turfgrass field riding on the mower tractor at a speed of $0.5 \mathrm{~m} / \mathrm{s}$ together with the position information gathered by a GPS receiver. The camera was connected to a laptop and the LabVIEW program (ver. 2012; National Instruments; Austin, Texas, USA) was used to acquire the images. Position coordinates of the Zoysia grass measuring points were obtained using RTK-GPS (model: A220, Hemisphere GPS Co., USA). All of the data were stored in the computer in real time. The data were then merged by software using the Matlab program (version
R2011a, Math Works, USA).

\section{Variable fertilizer recommendation procedure}

In our previous research (Kabir et al., 2016), grass images were acquired from turfgrass fields with 90\%, $70 \%$, and $50 \%$ growth coverage during static, vibration, and travelling conditions to reflect the grass coverages. The grass images collected from those three fields were processed through the color image segmentation (CIS) process, which was based on the gray level image segmentation approach (histogram thresholding) in the RGB color space. The excess green index (ExG) defined by Woebbecke et al. (1995) was employed for the RGB images and binarized by a thresholding method (Gée et al., 2008) to the smoothed ExG images considering the white pixels. Fig. 4 shows the total color image segmentation process such as an original image in the RGB color space of a grass field, excess green index (ExG), and finally thresholded binary image. The percentages of grassless area expressed as CIS values (\%) were calculated from the images by taking all white pixel values for determining the grass growth levels. From the image analysis results, the Zoysia grass growth levels of the three different sod production fields were divided into 10 levels from 1 (grassless) to 10 (well grown).

Calibration between the image processed results (i.e., CIS (\%)) and grass growth levels was done for measuring the grass growths of the experimental sod production fields with 90\%, 70\%, and 50\% grass growth coverage. Based on the calibration between CIS and grass growth levels of three different turfgrass fields, turfgrass growth levels were divided into levels from 0 (0\%) to 10 (100\%) and inverse relationships were obtained between the growth levels and fertilization recommendations to calculate every point's fertilization levels. Similar to the turfgrass growth levels of the sod pro-

Table 1. Specifications of the CCD camera used for taking images

\begin{tabular}{ccc}
\hline \multicolumn{2}{c}{ Specifications } \\
\hline CCD camera & Model & DFK 31BF03, Sony Co. (Japan) \\
& Size (mm) & $50.6 \times 50.6 \times 130(\mathrm{H} \times \mathrm{W} \times \mathrm{L})$ \\
& Resolution $(\mathrm{mm})$ & $1280 \times 960$ \\
Camera speed (images/s) & Up to 30 \\
Interface & IEEE-1394/GigE \\
\hline
\end{tabular}
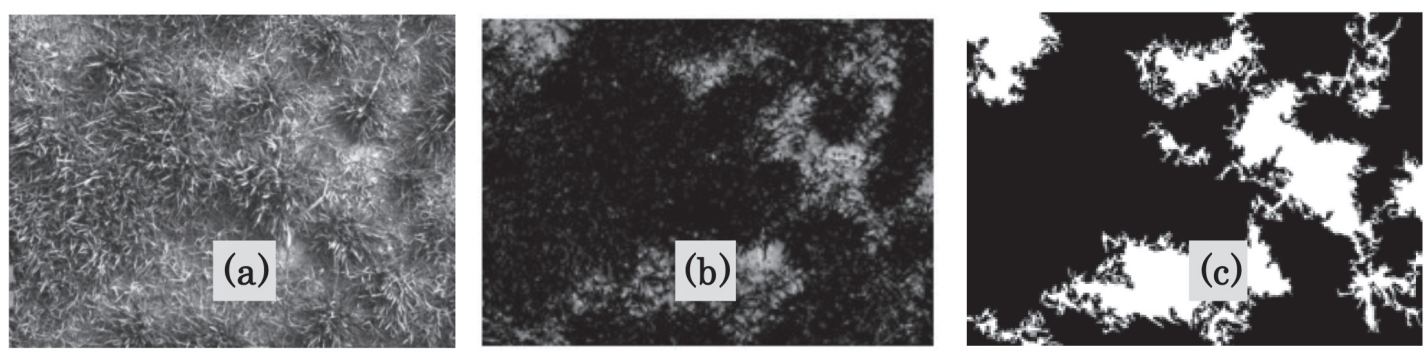

Fig. 4. Steps in image processing for color image segmentation (CIS) calculation: (a) Original image; (b) excess green index; (c) thresholded binary image. 
duction fields, fertilizer levels of 10 (100\%) to 0 (0\%) were accordingly recommended. The inverse linear relationship between fertilizer recommendation $(F R)$ and Zoysia grass growth $(G G)$ was derived by the equation below, where values " $a$ " and " $c$ " could be selected based on the grass growth status:

$$
F R=a \times G G+c
$$

The turfgrass growth and fertilizer recommendation maps were created based on the GPS coordinates to reflect the required amount of fertilizer for the target area. Recommended fertilization levels and growth levels of the linear inverse relationship were confirmed by the same variogram results. Those models and coordinates were used and input in GS+ software version 7.0 (Gamma Design Software, Plainwell, Michigan) to create the three fields' growth and fertilization level maps.

\section{Interpolation and mapping}

Geostatistical analysis was performed to characterize the spatial variation of the Zoysia grass growth using GS+ software. A semivariogram was produced for each of the Zoysia grass field to ascertain the degree of spatial variability between neighboring observations. Isotropic models for semivariograms were fitted as no anisotropy evident in directional semivariograms for grass growth. For fitting the semivariogram models, model parameters such as $\mathrm{C}_{0}$ (nugget effect), $\mathrm{C}_{0}+\mathrm{C}$ (sill), $\mathrm{A}_{0}$ (range), $\mathrm{R}^{2}$ (coefficient of determination), and RSS (residual sum of square errors) were adjusted. $R^{2}$ and RSS were used to select the best models and model parameters were determined.

In the 90\% turfgrass growth field, for the semivariance calculation minimum and maximum lag distances were $0.67 \mathrm{~m}$ and $20.0 \mathrm{~m}$, respectively. The lag interval was $1.0 \mathrm{~m}$ with a minimum number of pairs of 4269 . For the $70 \%$ turfgrass growth field, the maximum lag distance was $25.0 \mathrm{~m}$ with a lag interval of $1.0 \mathrm{~m}$ and led to at least 1480 pairs of data points. Whereas, for the 50\% turfgrass growth field, the maximum lag distance was $45.0 \mathrm{~m}$ with a lag interval of $1.4 \mathrm{~m}$, leading to at least 4099 pairs of data points.

The Kriging interpolation method, which uses semivariograms to express spatial continuity, was used to estimate the values of the selected grass growth properties at unsampled locations and to generate the estimated grass growth and fertilizer recommendation maps from the scattered set of image acquisition points. In this interpolation method, the estimates were based on values at neighboring locations with the spatial relationships. Block Kriging interpolation using 16 neighbor values was done for each of the fields as this value was usually sufficient. The radius values were 49.3, 55.5, and 93.2 for $90 \%, 70 \%$, and 50\% turfgrass growth fields, respectively. The interpolated Zoysia grass growth and fertilizer recommendation data were mapped for three different fields from the Kriging analysis. The maps were created with equal intervals of $0.15 \mathrm{~m}, 0.14 \mathrm{~m}$, and $0.29 \mathrm{~m}$ for $90 \%, 70 \%$, and 50\% turfgrass growth fields, respectively.

\section{RESULTS AND DISCUSSION}

\section{Grass growth calibration}

In our previous research (Kabir et al., 2016), the CIS values and grass growth levels of three different turfgrass field showed linear relationships. During the static condition, the CIS values and grass growth levels showed a linear relationship with $R^{2}$ value of 0.143 , while $R^{2}$ value of 0.256 was found for the moving condition. The significance of the slopes of the regression lines was also tested by t-test and no significance differences were found at a 5\% significance level.

Based on our previous findings, calibrations between the CIS values (\%) and grass growth levels were done for each of the experimental sod production fields with $90 \%, 70 \%$, and 50\% grass growth coverage to quantify the turfgrass growth levels. The turfgrass growth levels of the sod production fields were divided into 10 levels to allow the operator to use an average amount of fertilizer based on the turfgrass growth conditions in each area of the fields. The CIS values were found in a range of 0.32 to $8.8 \%$ for the $90 \%$ grass growth coverage field with more growth coverage in the range of 5.0 to 10.0 growth levels. A range of 3.5 to $14.0 \%$ CIS values was found for the $70 \%$ grass growth coverage field with more growth coverage in the range of 4.0 (40\%) to 9.0 (90\%) growth levels. Whereas, the CIS values were found in a range of 7.5 to $17.5 \%$ for the $50 \%$ grass growth coverage field with more growth coverage in the range of 1.0 (10\%) to 5.0 (50\%) growth levels (Fig. 5).

\section{Relationships among grass growth and fertilizer level}

Relationships between the image analysis results expressed in CIS (\%) and zoysia grass growth level were identified for each zoysia grass field. In the $90 \%$ grass growth coverage field, the CIS values and the zoysia grass growth levels exhibited a linear relationship with $85.3 \%$ variance. The $\mathrm{R}^{2}$ value $(0.916)$ was found highest for the $70 \%$ grass growth coverage field. Lower accuracy was achieved for the $50 \%$ grass growth coverage field with an $\mathrm{R}^{2}$ value of 0.673 . The scatter plots between the CIS value and grass growth $(G G)$ level of the three different fields are shown in Fig. 5 (left), and their relationships could be expressed by the following equations:

$$
\begin{aligned}
& G G_{1}=0.96 \times C I S_{1}+1.4(\text { Field } 1: 90 \% \text { coverage }) \\
& G G_{2}=0.71 \times C I S_{2}-0.21(\text { Field } 2: 70 \% \text { coverage }) \\
& G G_{3}=0.52 \times C I S_{3}-0.74(\text { Field } 3: 50 \% \text { coverage })
\end{aligned}
$$

Where, $C I S_{1}, C I S_{2}$, and $C I S_{3}$ are the image processed values and $G G_{1}, G G_{2}$, and $G G_{3}$ are the grass growth levels for the $90 \%, 70 \%$ and $50 \%$ grass growth coverage fields, respectively.

In addition, inverse linear relationships between grass growth $(G G)$ level and fertilizer recommendation $(F R)$ were also found for each field. The Zoysia grass status was different in the same sod production field; therefore, different levels of fertilization were required. The relationship between grass growth level and ferti- 

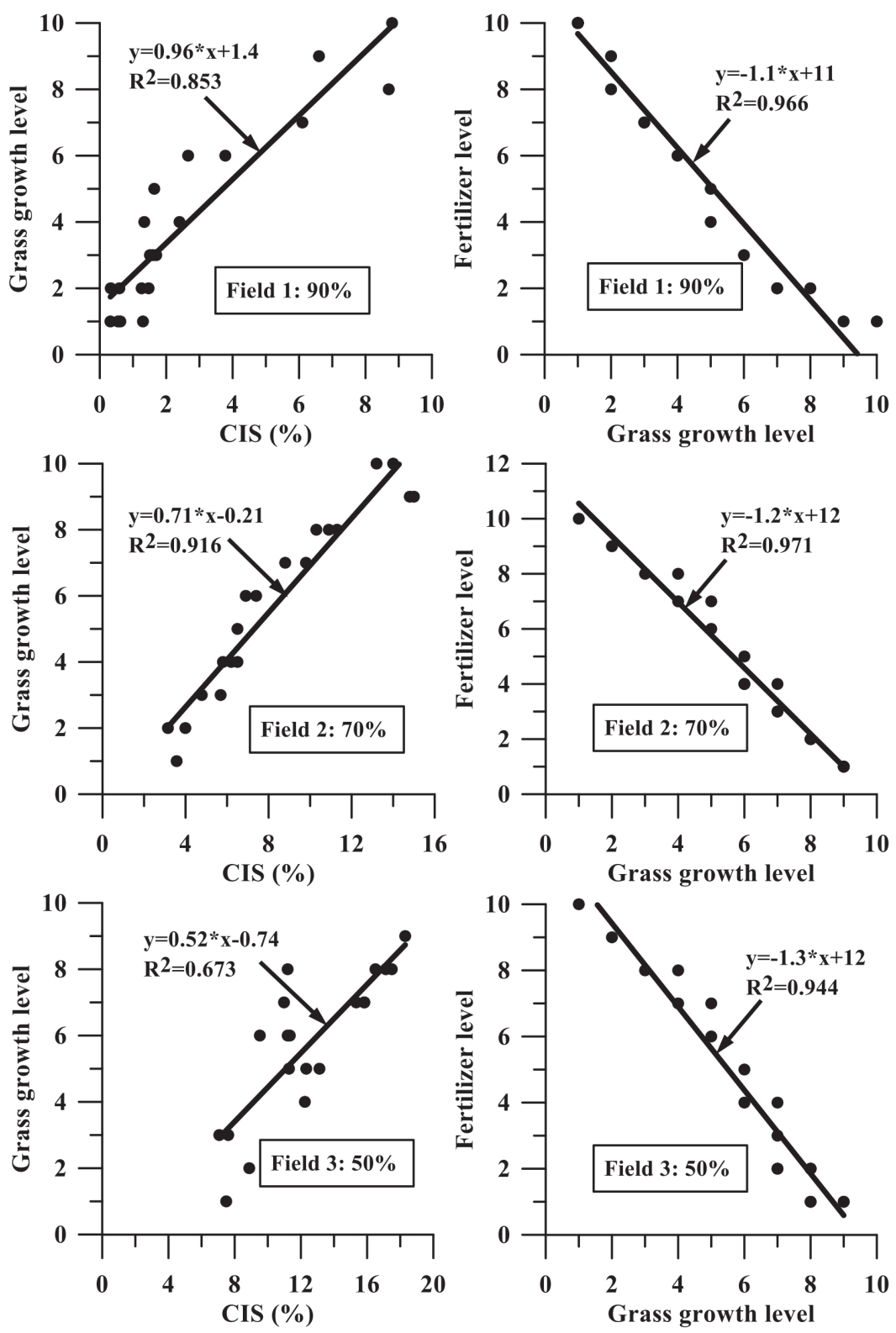

Fig. 5. Relationships between CIS (\%) vs. growth levels (left) and grass growth levels vs. fertilization levels (right) for different grass growth coverages.

lizer recommendation exhibited a linear relationship with $96 \%$ variance in the $90 \%$ grass growth coverage field. Higher accuracy was achieved $\left(\mathrm{R}^{2}=0.971\right)$ between grass growth levels and fertilizer recommendation for the $70 \%$ grass growth coverage field. Lower accuracy was found for the 50\% grass growth coverage field with an $\mathrm{R}^{2}$ value of 0.944 . The scatter plots between the $G G$ level and $F R$ for three different fields are shown in Fig. 5 (right), and their relationships could be expressed by the following equations:

$$
\begin{aligned}
& F R_{1}=-1.1 \times G G_{1}+11(\text { Field } 1: 90 \% \text { coverage }) \\
& F R_{2}=-1.2 \times G G_{2}+12(\text { Field } 2: 70 \% \text { coverage) } \\
& F R_{3}=-1.3 \times G G_{3}+12(\text { Field } 3: 50 \% \text { coverage })
\end{aligned}
$$

Where, $F R_{1}, F R_{2}$, and $F R_{3}$ are the fertilizer recommendations for the $90 \%, 70 \%$ and $50 \%$ grass growth coverage fields, respectively. The fertilizer application maps were prepared according to the grass growth zone maps indicating the variable fertilization required for each zone.

\section{Variability analysis and mapping}

The fitted semivariogram models for three experimental fields are shown in Fig. 6. In the 90\% turfgrass growth field, the nugget value optimized by different models varied by $0.35 \%$ (exponential model) to $0.72 \%$ (linear model). The value of sill varied from $0.92 \%$ (linear to sill model) to $1.03 \%$ (linear model). The optimized range values varied widely, from $1.90 \mathrm{~m}$ (exponential model) to $19.50 \mathrm{~m}$ (linear model). For the 70\% turfgrass growth field, the nugget values were optimized by different models varying from $0.64 \%$ (exponential model) to $0.96 \%$ (linear model). The value of sill varied from $1.41 \%$ (linear to sill model) to $1.56 \%$ (linear 

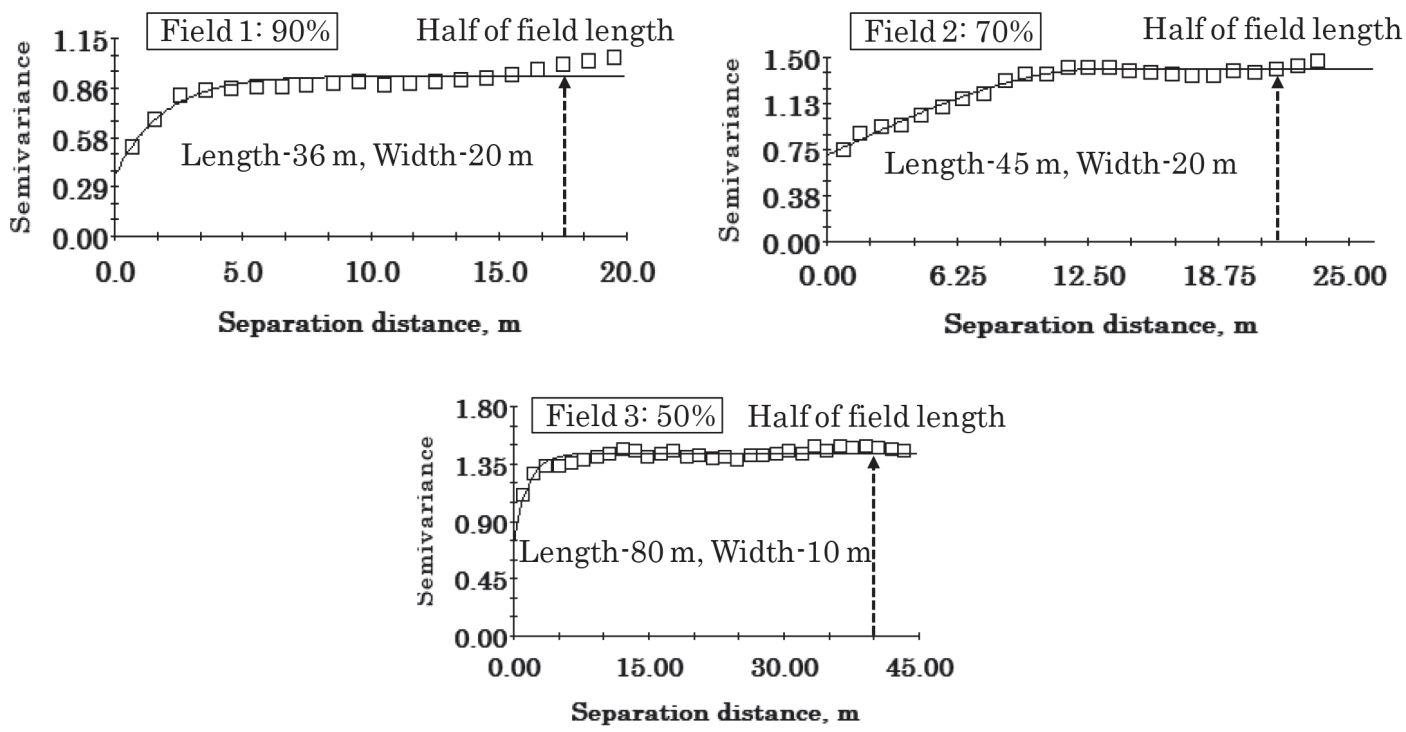

Fig. 6. Semivariograms of three Zoysia grass fields with their best fitted curves and parameters.

model). The optimized range values varied widely, from $5.74 \mathrm{~m}$ (exponential model) to $24.49 \mathrm{~m}$ (linear model). Similarly, a wide range of optimized parameter values were found in different semivariogram models for the $50 \%$ turfgrass growth field. The optimized nugget values varied in different models from $0.65 \%$ (linear to sill model) to $1.32 \%$ (linear model). A wide range of sill values from 1.42\% (linear to sill model) to 1.50\% (linear model) and range values from 1.20\% (Gaussian model) to $43.30 \%$ (linear model) were found for the $50 \%$ turfgrass growth field.

In this study, isotropic exponential and spherical models were fitted to the experimental semivariograms. The optimized semivariogram parameter (nugget, sill, and range) values of the fitted semivariogram models are presented in Table 2. The exponential model was found to best fit data for turfgrass the field with $90 \%$ growth coverage. The $\mathrm{R}^{2}$ values ranged from 0.696 (linear model) to 0.843 (exponential model) and the RSS values ranged from 0.039 (exponential model) to 0.679 (linear model). The spherical (SPHR) and linear to sill (LTIS) models were very close, indicating a close performance of the models for the turfgrass field with $70 \%$ growth. The performance of the linear to sill (LTIS) model is also

Table 2. Growth level and fertilization level isotropic variogram parameters of three fields

\begin{tabular}{cccccccc}
\hline Model* & Field & Nugget $\left(\mathrm{C}_{0}\right)$ & Sill $\left(\mathrm{C}_{0}+\mathrm{C}\right)$ & Range $(\mathrm{A} 0)$ & $\mathrm{Q}\left(\mathrm{C} / \mathrm{C}_{0}+\mathrm{C}\right)$ & $\mathrm{R}^{2}$ & $\mathrm{RSS}$ \\
\hline \multirow{2}{*}{ EXPN } & $90 \%$ & 0.346 & 0.933 & 1.900 & 0.629 & 0.843 & 0.039 \\
& $70 \%$ & 0.644 & 1.451 & 5.740 & 0.556 & 0.949 & 0.053 \\
& $50 \%$ & 0.711 & 1.435 & 1.560 & 0.505 & 0.780 & 0.040 \\
\hline \multirow{2}{*}{ SPHR } & $90 \%$ & 0.407 & 0.920 & 4.390 & 0.558 & 0.804 & 0.048 \\
& $70 \%$ & 0.703 & 1.407 & 13.17 & 0.500 & 0.968 & 0.036 \\
& $50 \%$ & 0.714 & 1.429 & 3.250 & 0.500 & 0.666 & 0.061 \\
\hline \multirow{2}{*}{ LITS } & $90 \%$ & 0.413 & 0.917 & 3.080 & 0.550 & 0.793 & 0.051 \\
& $70 \%$ & 0.704 & 1.409 & 9.940 & 0.500 & 0.965 & 0.037 \\
GAUS & $50 \%$ & 0.654 & 1.424 & 1.710 & 0.541 & 0.568 & 0.075 \\
\hline \multirow{2}{*}{ LINR } & $90 \%$ & 0.460 & 0.921 & 2.060 & 0.501 & 0.805 & 0.049 \\
& $50 \%$ & 0.710 & 1.421 & 6.050 & 0.500 & 0.958 & 0.066 \\
& $90 \%$ & 0.703 & 1.426 & 1.200 & 0.507 & 0.600 & 0.071 \\
\hline
\end{tabular}

* EXPN-exponential model, LITS-linear to sill, SPHR-spherical, GAUS-Gaussian, LINR-linear model 
acceptable as the $\mathrm{R}^{2}$ and RSS values were very similar for the $70 \%$ growth field with $\mathrm{R}^{2}$ values ranging from 0.735 (linear model) to 0.968 (spherical model) and RSS values ranging from 0.036 (spherical model) to 2.86 (linear model).

The Kriging interpolated maps of turfgrass growth and fertilizer recommendation showed gradual and nonrandom spatial variability across the grass field. Fig. 7 shows the grass growth and fertilizer application maps for $90 \%, 70 \%$, and $50 \%$ sod production fields. Five levels of Zoysia grass growth status and fertilizer were recommended based on the Zoysia grass growth coverage of the experimental fields. These maps illustrate the Zoysia grass growth and recommended fertilizer variations within the field. In the field with $90 \%$ growth coverage, higher growth was found in the middle area of the field in the range of 8.0 (80\%) to 9.0 (90\%) growth levels, and some edges of the experimental field showed less growth in the range of 5.0 (50\%) to 6.0 (60\%) levels. Therefore, lower fertilizer levels in the range of 0.5
(5\%) to $1.0(10 \%)$ in the middle area and higher fertilizer level in the range of 3.5 (35\%) to 4.7 (47\%) in the edges of the field were recommended.

Moderate grass growth variations were found in the $70 \%$ growth coverage field; some areas in the middle of the field were found to have higher and moderate grass growth coverage in the range of 8.0 (80\%) to 9.0 (90\%) levels. Some edges of the field were found to have a grass growth level of less than 5.0 (50\%). Hence, a lower fertilizer level in the range of 0.5 (5\%) to 1.5 $(15 \%)$ in the middle area and higher fertilizer level in the range of 3.0 (30\%) to 4.0 (40\%) in the edges of the field was recommended.

Whereas, high grass growth variations were found in the 50\% grass growth coverage field, showing less grass growth in most of the middle area of the field in the range of $4.0(40 \%)$ to 5.0 (50\%) and some edges of the field with high growth coverage in the range of 6.0 (60\%) to $7.0(70 \%)$ levels. Therefore, fertilizer recommendations also varied over the field, showing a higher
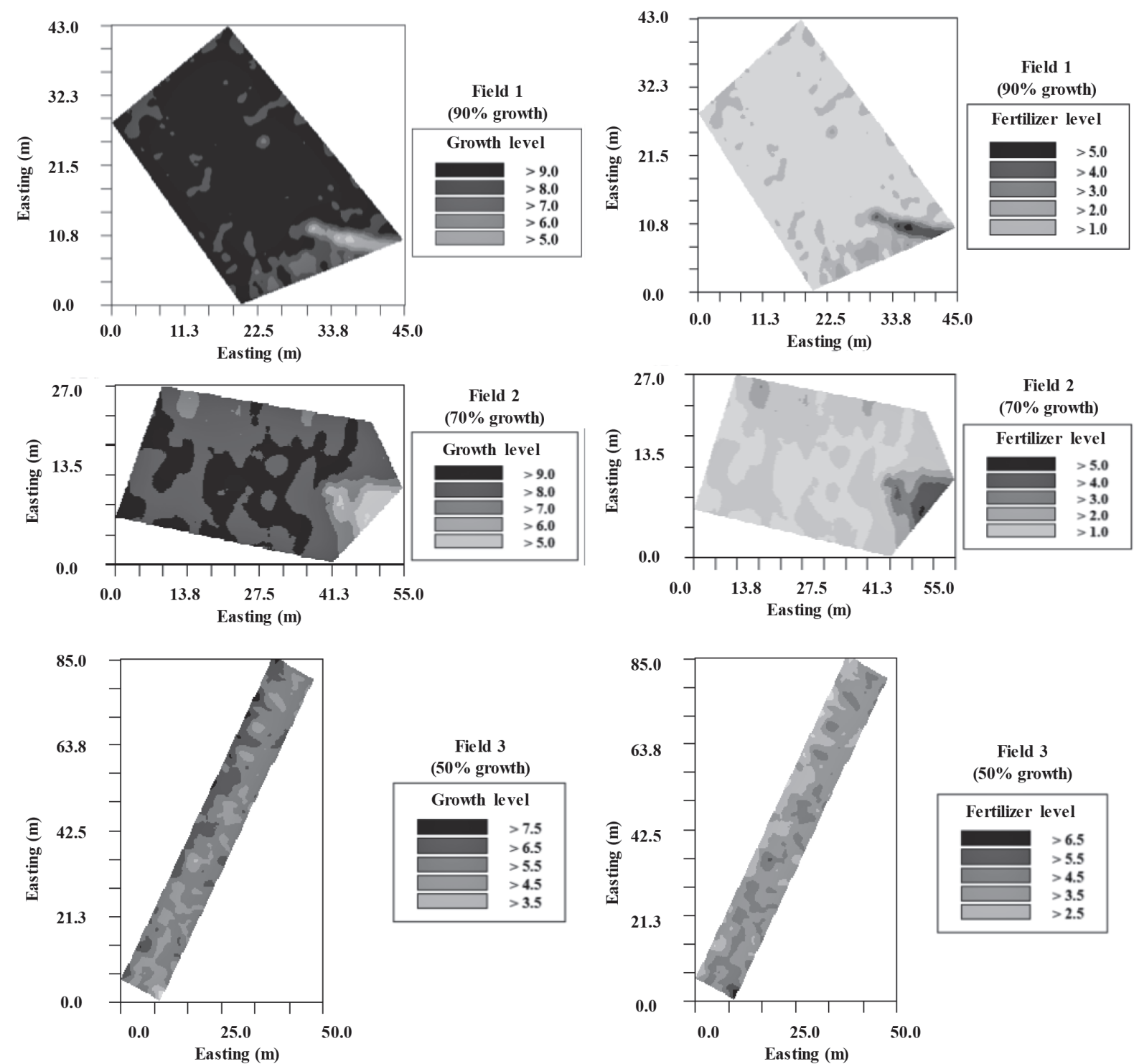

Fig. 7. Grass growth (left) and fertilizer application (right) maps for the fields with grass growth coverage levels of $90 \%$, $70 \%$, and $50 \%$. 
fertilizer rate in the range of 2.0 (20\%) to 4.0 (40\%) levels in the middle part of the field and a fertilizer level of 2.0 (20\%) to 3.0 (30\%) was recommended in some edges of the field.

\section{Economic benefits of VRF}

A uniform fertilizer application rate of 10 (100\%) level would require roughly $260 \mathrm{~kg} \mathrm{~N} / \mathrm{ha}, 280 \mathrm{~kg} \mathrm{~N} / \mathrm{ha}$, and $275 \mathrm{~kg}$ N/ha for the $90 \%, 70 \%$, and 50\% grass growth coverage fields. Comparing uniform fertilization to these fields, if the recommended fertilizers were variably applied it could save roughly $23.5 \%, 16.5 \%$, and $18.5 \%$ per hectare for the $90 \%, 70 \%$, and $50 \%$ coverage fields. Although nutritional input varies depending on climate zone, soil type, or species, the general yearly requirements for Zoysia grass are recommended at $10 \mathrm{~g} \mathrm{~N} / \mathrm{m}^{2}$, 19.5 to $29 \mathrm{~g} \mathrm{~N} / \mathrm{m}^{2}$, and $34.2 \mathrm{~g} \mathrm{~N} / \mathrm{m}^{2}$ for lower (i.e., home lawn), medium (i.e., golf course fairway, athletic field), and higher maintenance areas (i.e., higher leaching soil, sod production field), respectively (Carroll et al., 1996; Patton et al., 2017). According to the reported nutritional recommendation and field map images, nitrogen fertilizer in the Zoysia grass sod production field can be applied at a minimum rate of $23 \mathrm{~g} \mathrm{~N} / \mathrm{m}^{2}$ per year for medium to high growth level areas (i.e., growth levels 6 to 9 for $70 \%$ or $90 \%$ covered field), while up to 30 $\sim 34.2 \mathrm{~g} \mathrm{~N} / \mathrm{m}^{2}$ per year for $<4$ growth level areas such as the $50 \%$ covered field.

If this system is applied to a golf course fairway established with Korean lawngrass ( $Z$. japonica), where the recommendation rate ranges from 20 to $30 \mathrm{~N} / \mathrm{m}^{2}$ per year, the highest growth level area $(>9)$ with medium soil $\mathrm{P}$ and $\mathrm{K}$ contents will have a 4:1:2 ratio of $\mathrm{N}: \mathrm{P}_{2} \mathrm{O}_{5}: \mathrm{K}_{2} \mathrm{O}$, which equals to $19.5 \mathrm{~g} \mathrm{~N}, 4.8 \mathrm{~g} \mathrm{P}_{2} \mathrm{O}_{5}$, and $9.6 \mathrm{~g} \mathrm{~K}_{2} \mathrm{O}$ per square meter per year with the application of about $115 \mathrm{~g}$ of a compound fertilizer (16:4:8) (www. aesl.ces.uga.edu). A higher rate will be required for the lower growth level segments $<4$ or if clippings are removed, where the compound fertilizer will be increased up to $172 \mathrm{~g}$ per square meter per year (divided by about $43 \mathrm{~g}$ in spring, June, July, and September).

Variable rate fertilization is promising and could save a big amount of fertilizer. But uniform fertilization with an average amount of fertilizer could enhance fertilizer use efficiency. Farmers could take some images from well-grown to less grown areas of a grass field and based on the growth calibration shown in this study, the recommended fertilizer could be set for the entire field for real-time fertilizer application.

\section{CONCLUSIONS}

Aiming at variable fertilizer recommendations for sod production fields, an image-based variable rate fertilization system was developed in this study. A CCD camera was mounted on the top front of a mower tractor and Zoysia grass images were acquired from three different sod production fields with coverage density of about 90\%, 70\%, and 50\%. Based on the calibration between image processed results (i.e., CIS values) and grass growth levels in our previous research (Kabir et al., 2016), Zoysia grass growth levels for the three different sod production fields were quantified with position information gathered by GPS.

Linear relationships among the CIS values and zoysia grass growth levels were identified and inverse relationships were derived for variable fertilizer recommendations. The relationships between grass growth levels and fertilizer recommendations exhibited linear relationships for the three different fields. Variations in the growth levels of the Zoysia grass were found for the same field; therefore, different levels of fertilization were recommended.

Semi-variance analyses were carried out to characterize the spatial Zoysia grass growth distribution. The best semivariogram model was selected comparing the $\mathrm{R}^{2}$ and RSS values for different lag sizes and lag intervals. The exponential models fit well for the 90\% and 50\% grass growth coverage field, whereas a spherical model was found to be the best fit for the $50 \%$ grass growth coverage field. The Kriging interpolated Zoysia grass growth and fertilizer recommendation data were mapped to show gradual and non-random spatial variability for three experimental sod production fields. This variable fertilizer recommendation system with average amounts of fertilizer could enhance fertilizer use efficiency, reflecting grass growth status effectively for sod production and could help operators to achieve efficient variable fertilization.

\section{ACKNOWLEDGEMENTS}

This work was supported by research fund of Chungnam National University.

\section{AUTHOR CONTRIBUTIONS}

Md. Shaha Nur KABIR performed the experiments, analyzed the data, and prepared the draft manuscript. Sun-Ok CHUNG designed and supervised the research. Bo-Eun JANG assisted the experiments and data analysis. Yong-Joo KIM participated in the design and data analysis. Geung-Joo LEE advised grass growth quantification and fertilizer recommendation. Kyeong-Hwan LEE contributed preparation of the equipment and data collection. Takashi OKAYASU and Eiji INOUE advised data analysis and manuscript revision. All authors assisted in editing of the manuscript and approved the final version.

\section{REFERENCES}

Aitkenhead, M., I. Dalgetty, C. Mullins, A. McDonald and N. Strachan 2003 Weed and crop discrimination using image analysis and artificial intelligence methods. Comput. Electron. Agric., 39: 157-171

Aldous, D. E., K.W. McAuliffe and N. M. Power 2007 The turfgrass industry: Australia, New Zealand, and the Asia-Pacific region. Chronica Hort., 47: 17-19

Andreasen, C., M. Rudemo and S. Sevestre 1997 Assessment of weed density at an early stage by use of image processing. Weed Res., 37: 5-18 
Bean, B., J. McAfee, E. Bynum, R. French and N. Kenny 2012 Turfgrass management for the Texas Panhandle. AgriLife Extension, The Texas A\&M University System, U.S. Department of Agriculture. Available at http://amarillo.tamu.edu/ files/2010/11/Turfgrass-Management-Web-Version\%5E4-16-12. pdf

Basso, B., J. T. Ritchie, D. Cammarano and L. Sartori 2011 A strategic and tactical management approach to select optimal $\mathrm{N}$ fertilizer rates for wheat in a spatially variable field. Eur. $J$. Agron., 35: 215-222

Basso, B., B. Dumont, D. Cammarano, A. Pezzuolo, F. Marinello and L. Sartori 2016 Environmental and economic benefits of variable rate nitrogen fertilization in a nitrate vulnerable zone. Sci. Total Environ., 545-546: 227-235

Burgos-Artizzu, X. P., A. Ribeiro, M. Guijarro and G. Pajares 2011 Real-time image processing for crop/weed discrimination in maize fields. Comput. Electron. Agric., 75(2): 337-346

Carey, R. O., G. J. Hochmuth, C. J. Martinez, T. H. Boyer, V. D. Nair, M. D. Dukes, G. S. Toor, A. L. Shober, J. L. Cisar, L. E. Trenholm and J. B. Sartain 2012 A review of turfgrass fertilizer management practices: Implications for urban water quality. HorticTech. 22(3): 280-291

Carroll, M. J., P. H. Dernoeden and J. M. Krouse 1996 Zoysia grass establishment from sprigs following application of herbicides, nitrogen, and a biostimulator. HortScience, 31: 972-975

Chan, K. L. and K. McCarty 1990 Aspects of the statistical texture analysis of medical ultrasound images. In: "IEE Colloquium on Ultrasound Instrumentation," pp. 1/3-3/3

Chan, C. W., J. K. Schueller, W. M. Miller, J. D. Whitney, T. A. Wheaton and J. A. Cornell 2002 Error sources on yield-based fertilizer variable rate application maps. Precision Agric., 3: $81-94$

Choi, J. S. and G. M. Yang 2006 Sod production in South Korea. Asian J. Turfgrass Sci, 20: 237-251

Duble, R. L. 2001 Turfgrasses: Their Management and Use in the Southern Zone, $2^{\text {nd }}$ ed. Texas A\&M University Press, Texas (USA) pp. 152-167

Farooque, A. A., Q. U. Zaman, A. W. Schumann, A. Madani and D. C. Percival 2012 Delineating management zones for site-specific fertilization in wild blueberry fields. Appl. Eng. Agric., 28(1): $57-70$

Fricke T., F. Richter and M. Wachendorf 2011 Assessment of forage mass from grassland swards by height measurement using an ultrasonic sensor. Comput. Electron. Agric., 79: 142-152

Gée, Ch., J. Bossu, G. Jones and F. Truchetet 2008 Crop/weed discrimination in perspective agronomic images. Comput. Electron. Agric., 60: 49-59

Gourevitch, J. D., B. L. Keeler and T. H. Ricketts 2018 Determining socially optimal rates of nitrogen fertilizer application. Agric. Ecosyst. Environ., 254: 292-299

Grisso, R. B., M. Alley, W. Thomason, D. Holshouser and G. T. Roberson 2011 Precision Farming Tools: Variable-Rate Application. Publication \# 442-505, Virginia Polytechnic Institute and State University, Virginia Tech, Blacksburg

Ha, N., T. Feike, H. Back, H. Xiao and E. Bahrs 2015 The effect of simple nitrogen fertilizer recommendation strategies on product carbon footprint and gross margin of wheat and maize production in the North China Plain. J. Environ. Manage., 163: 146154

Haydu, J. J., W. A. Hodges and C. R. Hall 2006 Economic impacts of the turfgrass and lawncare industry in the United States, Publication \# FE632, Food and Resource Economics Department, UF/IFAS Extension, University of Florida

Huang, Y., S. J. Thomson, W. C. Hoffmann, Y. Lan and B. K. Fritz 2013 Development and prospect of unmanned aerial vehicle technologies for agricultural production management. Int. J. Agric. \& Biol. Eng., 6(3): 1-10

Kabir, M. S. N., S. O. Chung, Y. J. Kim, G. J. Lee, S. H. Yu, K. H. Lee, T. Okayasu and E. Inoue 2016 Sensor comparison for grass growth Estimation. J. Fac. Agr., Kyushu Univ., 61(2): 367374
Koch, B., R. Khosla, W. M. Frasier, D. G. Westfall and D. Inman 2004 Economic feasibility of variable-rate nitrogen application utilizing site-specific management zones. Agron. J., 96(6): $1572-1580$

Korea Forest Service 2012 Production survey of forest products in 2011. Korea Forest Service, Daejeon (Korea) p. 588

Liu C., Y. Liu, Z. Li, G. Zhang and F. Chen 2017 A novel way to establish fertilization recommendations based on agronomic efficiency and a sustainable yield index for rice crops. Sci. Rep., $\mathbf{7}(1): 1001$

Monteiro, J. A. 2017 Ecosystem services from turfgrass landscapes. Urban For. Urban Gree., 26: 151-157

Murdock, L. and P. Howe 1997 Profitability of variable rate fertilization on a Kentucky soil (a Theoretical Analysis). Soil Science News \& Views, Vol. 18, No. 10, Department of Agronomy, University of Kentucky, Lexington, Kentucky

Patton, A. J., B. M. Schwartz and K. E. Kenworthy 2017 Zoysia grass (Zoysia spp.) history, utilization, and improvement in the United States: a review. Crop Sci., 57: S-37-S-72

Pérez, A., F. López, J. Benlloch and S. Christensen 2000 Colour and shape analysis techniques for weed detection in cereal fields. Comput. Electron. Agric., 25: 197-212

Philipp, I. and T. Rath 2002 Improving plant discrimination in image processing by use of different colour space transformations. Comput. Electron. Agric., 35: 1-15

Pittman J, D. Arnall, S. Interrante, C. Moffet and T. Butler 2015 Estimation of biomass and canopy height in bermudagrass, alfalfa, and wheat using ultrasonic, laser, and spectral sensors. Sensors, 15(2): 2920-2943

Raun, W. R., J. B. Solie, M. L. Stone, K. L. Martin, K. W. Freeman, R. W. Mullen, H. Zhang, J. S. Schepers and G. V. Johnson 2005 Optical sensor-based algorithm for crop nitrogen fertilization. Commun. Soil. Sci. Plant. Anal., 36: 2759-2781

Reyes, J. F., W. Esquivel, D. Cifuentes and R. Ortega 2015 Field testing of an automatic control system for variable rate fertilizer application. Comput. Electron. Agric., 113: 260-265

Ribeiro, A., C. Fernández-Quintanilla, J. Barroso and M. C. GarcíaAlegre 2005 Development of an image analysis system for estimation of weed. In: Proceedings of the $5^{\text {th }}$ European Conference on Precision Agriculture (5ECPA), pp. 169-174

Rosenfeld, A. and A. C. Kak 1982 Digital Picture Processing, Vol. $1,2^{\text {nd }}$ ed. Academic Press, Boston, MA (USA)

Ruicheng, D., G. Bingcai, L. Ningning, W. Chenchen, Y. Zidong and M. Mingjian 2013 Design and experiment on intelligent fuzzy monitoring system for corn planters. Int. J. Agric. \& Biol. Eng., 6(3): 11-18

Tuceryan, M. and A. K. Jain 1998 Texture Analysis. In: "Handbook of Pattern Recognition and Computer Vision $\left(2^{\text {nd }}\right.$ edition)", ed. by C. H. Chen, L. F. Pau and P. S. P Wang, World Scientific Publishing Co., Singapore, pp. 207-248

Van Evert, F. K., G. W. A. M. Van Der Heijden, L. A. P. Lotz, G. Polder, A. Lamaker, A. De Jong, M. C. Kuyper, E. J. K. Groendijk, J. J. Neeteson and A. J. A. Van Der Zalm 2006 A mobile field robot with vision-based detection of volunteer potato plants in a corn crop. Weed Technol., 20(4): 853-861

Wells, K. L. and J. E. Dollarhide 1998 Precision agriculture: The effect of variable rate fertilizer application on soil test values. Soil Science News and Views, 19(6)

White, R. W., J. L. Adrian and R. Dickens 1991 Alabama's turfgrass-sod industry. Bulletin \# 610, Alabama Agricultural Experiment Station, Auburn University

Woebbecke, D. M., G. E. Meyer, K. V. Bargen and D. A. Mortensen 1995 Color indices for weed identification under various soil, residue, and lighting conditions. Trans. ASAE, 38(1): 271-281

$\mathrm{Xu}, \mathrm{T} ., \mathrm{N}$. Su, R. Wang and L. Song 2015 A novel variable rate fertilization system based on the Android platform. In: 2015 EEE International Conference on Progress in Informatics and Computing (PIC), Nanjing, pp. 395-398

Xu, X., P. He, M. F. Pampolino, A. M. Johnston, S. Qiu, S. Zhao, L. Chuan and W. Zhou 2014a Fertilizer recommendation for maize in China based on yield response and agronomic efficiency. Field Crops Res. 157: 27-34 
Xu, X., P. He, S. Qiu, M. F. Pampolino, S. Zhao, A. M. Johnston and W. Zhou 2014b Estimating a new approach of fertilizer recommendation across smallholder farms in China. Field Crops Res. 163: $10-17$

Yang, C. C., S. O. Prasher, J. A. Landry and H. S. Ramaswamy 2003 Development of an image processing system and a fuzzy algorithm for site-specific herbicide applications. Precision Agric., 4: $5-18$

Yi, J. 2012 Economic analysis of turfgrass-sod production in Alabama. M. Sc. thesis, Auburn University, Auburn, Alabama (USA) $p p \cdot 1-5$
Ying-zi, Z., C. Hai-tao, H. Shou-yin, J. Wen-yi, O. Bin-lin, D. Guoqiang and Z. Ji-cheng 2015 Design and experiment of slave computer control system for applying variable-rate liquid fertilizer. J. Northeast Agric. Univ., 22(2): 73-79

Youn, J. H., J. P. Lee and D. H. Kim 2005 The present situation of patented technology on turfgrass cultivar in domestic and foreign. Asian J. Turfgrass Sci., 19(2): 141-149

Youn, J. H., J. P. Lee and D. H. Kim 2006 Commercialization of patented technology on turfgrass production in Korea. Asian $J$. Turfgrass Sci., 20(1): 107-118 